\title{
Cuidando de idosos com Alzheimer: a vivência de cuidadores familiares
}

\section{Caring for elders with Alzheimer's disease: experiences of family caregivers}

\author{
Cuidando de ancianos con Alzheimer: la vivencia de los cuidadores familiares
}

\author{
Sofia Cristina Iost Pavarini', Larissa Coelho de Melo", Viviane Manara Silva"', \\ Fabiana de Souza Orlandilv, Marisa Silvana Zazzetta de Mendiondo ${ }^{\mathrm{V}}$, \\ Carmen Lúcia Alves Filizolavı, Elizabeth J oan Barham ${ }^{\mathrm{VII}}$
}

\section{RESUMO}

A doença de Alzheimer causa comprometimento na capacidade funcional dos idosos, aumentando a demanda por cuidados. Este trabalho teve por objetivo compreender o processo de vivenciar o cuidado a idosos demenciados. Trata-se de um estudo descritivo e transversal, realizado de agosto-2005 a agosto-2006. Foram realizadas entrevistas domiciliárias com cuidadores familiares de idosos demenciados $(\mathrm{N}=14)$, usuários de uma unidade saúde escola. Os dados foram analisados segundo o modelo de Análise de Conteúdo- Análise Temática de Bardin. Os resultados mostram que o início da doença é, para a maioria dos cuidadores, confundido com o próprio processo de envelhecimento. Com a evolução da doença, aumenta a dependência dos idosos. As alterações de comportamento por parte do idoso causam grande impacto emocional nos cuidadores. Vivenciar a situação de cuidar de um idoso com Alzheimer é uma experiência que depende da fase da doença, da rede de suporte familiar e da história de cada família.

Palavras chave: Idoso; Família; Doença de Alzheimer; Cuidadores; Enfermagem geriátrica.

\footnotetext{
ABSTRACT

Alzheimer's disease compromises an elderly person's functional capacity, increasing his or her need for assistance. This study aimed to better understand processes involved in caring for elders with dementia. A descriptive, transversal method was used; data were collected between August, 2005 and August 2006. In-home interviews were conducted with family caregivers for demented elders $(N=14)$, service users at a school for healthcare practices. The data were analyzed using Bardin's model for Content and Theme Analysis. The results show that the majority of caregivers confuse the onset of the disease with normal aging processes. As the disease
}

progresses, the elders' dependence levels increase. The elders' behavior changes have a strong emotional impact on their caregivers. Some key factors that affect the caregiving experience include the stage of the disease, the strength of the family support network and family history.

Key words: Aged; Family; Alzheimer disease; Caregivers; Geriatric nursing.

\section{RESUMEN}

La enfermedad de Alzheimer causa comprometimiento de la capacidad funcional de los ancianos, aumentando la demanda de cuidados. Este trabajo tuvo como objetivo comprender el proceso de vivenciar el cuidado de los ancianos con demencia. Se trata de un estúdio descriptivo y transversal, realizado de

Enfermeira. Professora Doutora do Departamento de Enfermagem da Universidade Federal de São Carlos. Coordenadora do projeto que foi financiado pelo CNPq e pela Pró-Reitoria e Extensão da UFSCar. Líder do Grupo de Pesquisa Saúde e Envelhecimento do CNPq e Membro do Grupo de Pesquisa Saúde e Família. E-mail: sofia@power.ufscar.br.

"Enfermeira. Programa Unificado de Iniciação CientíficaUFSCar 2005-2006. E-mail: larissac_enf@yahoo.com.br.

III Enfermeira. Bolsista do PIBIC/CNPP-UFSCar. 2005-2006.

E-mail: vivi manara@yahoo.com.br.

`v Enfermeira da Unidade Saúde Escola da UFSCar até 2006. Mestre em Enfermagem pela UNICAMP. Membro do Grupo de Pesquisa Saúde e Envelhecimento. Email: fabi ferreira@yahoo.com.br.

${ }^{\vee}$ Assistente social. Doutora em Serviço Social pela Pontifícia Universidade Católica do Rio Grande do Sul, DoutoradoSanduíche com Gesamthochschule Kassel-Ghk em KasselAlemanha, Coordenadora do Idoso da unidade Saúde Escola-UFSCar. Membro do Grupo de Pesquisa Saúde e Envelhecimento. E-mail: marisam@power.ufscar.br.

vi Enfermeira. Professora Doutora do Departamento de Enfermagem da Universidade Federal de São Carlos. Líder do Grupo de Pesquisa Saúde Mental na Reforma Psiquiátrica e Membro do Grupo de Pesquisa Saúde e Família do CNPq. E-mail: filizola@power.ufscar.br.

VII Psicóloga. Doutora em Psicologia Social e de Desenvolvimento Aplicada. Membro do Grupo de Pesquisa Saúde e Envelhecimento. E-mail: lisa@power.ufscar.br. 
Pavarini SCl, Melo LC, Silva VM, Orlandi FS, Mendiondo MSZ, Filizola CLA et al. Cuidando de idosos com Alzheimer: a vivência de cuidadores familiares. Rev. Eletr. Enf. [Internet]. 2008;10(3):580-90. Available from:

agosto de 2005 a agosto de 2006. Fueron realizadas entrevistas domiciliares con cuidadores familiares de ancianos con demencia $(\mathrm{N}=14)$, usuarios de una Unidad de Salud Escuela. Los datos fueron analisados según el modelo de Análisis de Contenido- Análisis Temática de Bardin. Los resultados muestran que, para la mayoría de los cuidadores, el inicio de la enfermedad es confundido con el propio proceso de envejecimiento. Con la evolución de la enfermedad, aumenta la dependencia de los

\section{NTRODUÇÃO}

A população mundial está envelhecendo. Estima-se que no Brasil, até 2020, haverá mais de 30 milhões de idosos, o que representará $13 \%$ da população ${ }^{(1)}$. Na medida em que a população mundial envelhece, as doenças crônicas não transmissíveis (DCNT) também aumentam significativamente nos idosos.

Dentre as DCNT mais comuns, destaca-se a demência. Demência é entendida como uma síndrome, caracterizada clinicamente por declínio gradual nas funções cognitivas, mudanças de personalidade e comportamento e deterioração nas atividades da vida diária da pessoa acometida ${ }^{(2)}$.

As demências são identificadas como progressivas e degenerativas, repercutindo na situação de dependência e perda de autonomia do idoso(3), surgindo assim a necessidade de assistência e cuidados.

Estudos demonstram que a prevalência da demência dobra a cada cinco anos a partir dos 60 anos de idade. Após os 64 anos a prevalência é de cerca de 5 a $10 \%$, elevando para $30 \%$ entre aqueles com 85 anos $^{(4)}$. Em estudo populacional brasileiro realizado com idosos vivendo numa comunidade, a prevalência de demência variou de $1,6 \%$, entre os indivíduos com idade de 65 a 69 anos a 38,9\%, entre aqueles com idade superior a 84 anos $^{(5)}$.

A demência se caracteriza por: 1- Déficits cognitivos manifestados por comprometimento da memória e de uma ou mais funções corticais altas: linguagem (afasia), praxias, gnosias, função executiva; 2- Declínio cognitivo gradual e progressivo; 3- Exclusão da indução dos sintomas por substâncias ou outras doenças do SNC; 4- Alteração significativa na atividade ancianos. Las alteraciones de comportamiento causan gran impacto emocional en los cuidadores. Vivenciar la situación de cuidar de un anciano con Alzheimer es una experiencia que depende de la fase de la enfermedad, de la red de apoyo familiar y de la historia de cada familia.

Palabras clave: Anciano; Familia; Enfermedad de Alzheimer; Cuidadores; Enfermería geriátrica.

social ou profissional e 5- Os déficits não ocorrem exclusivamente durante episódio de delirium e não podem ser atribuídos à depressão ${ }^{(6)}$.

A doença de Alzheimer é a causa mais comum de demência no idoso. É consenso na literatura que a Doença de Alzheimer (DA) é a responsável por 50 a $60 \%$ dos casos de demência na população de idosos ${ }^{(3)}$. Trata-se de uma doença neurodegenerativa que se inicia geralmente com a perda de memória, acompanhada de outros sintomas cognitivos como afasia, apraxia e agnosia ${ }^{(4)}$.

A demência, considerada uma síndrome, caracteriza-se pelo comprometimento cognitivo e que traz como conseqüência a perda da capacidade funcional, aumentando a demanda por cuidados, que geralmente são cada vez mais complexos ${ }^{(7)}$. Causa um ônus crescente sobre o idoso e a família e um enorme custo financeiro para o sistema de saúde. A Doença de Alzheimer é apontada pelo relatório sobre a saúde mental no mundo, como um dos transtornos mentais de grande impacto negativo para a qualidade de vida dos indivíduos e famílias e que traz forte impacto econômico direto e indireto nas sociedades, incluindo o custo dos serviços ${ }^{(8)}$.

A presença de um parente com Doença de Alzheimer no meio familiar é uma situação potencialmente conflituosa e impulsionadora de tensões constantes, afetando diretamente o cuidador e a dinâmica familiar ${ }^{(9)}$.

O cuidar de um idoso com doença de Alzheimer acarreta sobrecarga física e emocional à vida do cuidador, associadas ao comprometimento das atividades da vida diária do idoso, principalmente no estágio grave ${ }^{(3)}$. 
Pavarini SCl, Melo LC, Silva VM, Orlandi FS, Mendiondo MSZ, Filizola CLA et al. Cuidando de idosos com Alzheimer: a vivência de cuidadores familiares. Rev. Eletr. Enf. [Internet]. 2008;10(3):580-90. Available from:

A sobrecarga emocional vivenciada pelo cuidador pode interferir no cuidado prestado ao paciente, sendo inclusive fator preditor de maior número de hospitalizações entre os pacientes $^{(10)}$, aumento de institucionalizações ${ }^{(11)}$ e maior mortalidade entre os cuidadores ${ }^{(12)}$.

Cuidar de um familiar com Alzheimer por vários anos é um processo que traz como conseqüência o desgaste físico e emocional para o cuidador principal e para toda a família. Tratase de uma experiência muito particular que provavelmente depende da história e da dinâmica de cada família. Por essa razão, o presente estudo teve como objetivo compreender o processo de vivenciar o cuidado a idosos com diagnóstico de Alzheimer.

\section{MÉTODO}

Trata-se de um estudo descritivo de abordagem qualitativa, realizado entre agosto de 2005 a agosto de 2006.

Participaram do estudo 14 cuidadores familiares de idosos com diagnóstico provável de Doença de Alzheimer, usuários de uma Unidade de Saúde Escola de um município do interior do Estado de São Paulo. A maioria do gênero feminino (86\%), com idade entre 39 e 80 anos e sem alterações cognitivas segundo um teste de rastreamento (Mini Exame do Estado Mental - MEEM).

Para a coleta de dados foram realizadas entrevistas nos domicílios dos cuidadores, após agendamento prévio. Duas questões nortearam as entrevistas: 1- Como tem sido para você vivenciar a situação de demência na família? 2Quais os cuidados que você precisa realizar para o idoso no desempenho de suas atividades de vida diária?

As entrevistas foram realizadas tendo em vista os preceitos éticos que regem pesquisas com seres humanos, sendo que a coleta de dados teve início após aprovação pelo Comitê de Ética em Pesquisa da instituição (Parecer CAAE 047/2006). Os cuidadores foram esclarecidos do objetivo da investigação e concordaram em participar assinando o Termo de Consentimento Livre e Esclarecido.

Na coleta de dados foi utilizado gravador e os dados foram transcritos posteriormente. Os dados foram codificados e agrupados em categorias, seguindo o modelo de Análise de Conteúdo, modalidade Análise Temática, proposto por Bardin ${ }^{(13)}$.

\section{RESULTADOS}

Vivenciar o cuidado ao idoso com Alzheimer é um processo longo e que se diferencia em cada fase da doença. No início ela é, para a maioria dos cuidadores familiares, confundida com o próprio processo de envelhecimento. As alterações de memória vão se tornando cada vez mais evidentes. A família passa a perceber que se trata de um processo crônico, degenerativo e que tende a piorar. $\mathrm{Na}$ fase intermediária da doença, as alterações de comportamento apresentadas pelos idosos causam grande impacto emocional aos cuidadores. Com a evolução do quadro, aumenta a dificuldade no desempenho das atividades de vida diária, e aumenta consequentemente a dependência dos idosos. Os entrevistados refletem sobre o processo de vivenciar o papel de cuidador que se soma a outros papéis que desempenha junto à família e sentem falta de apoio familiar. Assim, das análises das entrevistas foram apreendidas três categorias: Categoria 1-Descobrindo a doença; Categoria 2-Vivenciando as fases da doença e Categoria 3- Vivenciando o papel de cuidador.

\section{Descobrindo a doença}

Os cuidadores entrevistados apontam em seus relatos que o inicio da doença é muitas vezes confundido com o processo natural de envelhecimento. Esquecer passa a ser uma "coisa da idade", interferindo no diagnóstico precoce da demência.

Ah...foram...primeiro assim, ela depois que foi diagnosticado a doença, eu percebi que ela tinha esses sintomas há mais de 3 anos. 0 fato de esquecer, mas aquela coisa que a gente acha que todo mundo tem...de esquecer, de repetir a história várias vezes. (FRT)

...foi quando nós descobrimos que era o Alzheimer por que até então eles falavam que era uma esclerose, um esquecimento normal... Aí eu perguntei pra ele se era uma esclerose, por que eu achava que esclerose era uma coisa 
Pavarini SCl, Melo LC, Silva VM, Orlandi FS, Mendiondo MSZ, Filizola CLA et al. Cuidando de idosos com Alzheimer: a vivência de cuidadores familiares. Rev. Eletr. Enf. [Internet]. 2008;10(3):580-90. Available from:

da idade, não era uma doença mais grave, era um esquecimento normal devido a idade. (RMVL)

O diagnóstico precoce torna-se difícil, justamente pelo fato de que a doença de Alzheimer em seu estágio inicial pode ser confundida como uma manifestação natural, própria do processo de envelhecimento, como observamos nos relatos dos cuidadores. De início insidioso, com queixas de memória ou apatia, a doença de Alzheimer pode ser confundida, segundo especialistas, com depressão, perda de memória associada à idade ou sintomas que não são inicialmente notados pela família ou pelo próprio idoso ${ }^{(4)}$. Muitos idosos quando procuram ou são levados aos serviços de saúde muitas vezes se encontram em estágios mais avançados da doença.

A Classificação Internacional das Doenças define demência como uma síndrome, ou seja, um grupo de sinais e sintomas que podem ser causados por uma série de doenças subjacentes, relacionadas a perdas neuronais e danos à estrutura cerebral. O início da doença de Alzheimer surge na maioria das vezes com o prejuízo da memória. Além disso, a síndrome demencial inclui pelo menos um dos seguintes prejuízos cognitivos: afasia (prejuízo na linguagem secundário à ruptura da função cerebral); apraxia (incapacidade de realizar atividades motoras complexas, apesar da capacidade motora intacta); agnosia (falha em reconhecer ou identificar objetos, apesar de funções sensoriais intactas) e perturbação nas funções de execução, como planejamento, organização, seqüência e abstração(6). Torna-se importante considerar no âmbito da assistência à saúde do idoso uma atenção especial às pessoas que vivenciam um processo demencial, pois muitas vezes os sintomas iniciais são confundidos com o processo fisiológico do envelhecimento e são pouco percebidos pela família.

Um estudo epidemiológico realizado na cidade de Catanduva mostrou que $14 \%$ dos idosos que viviam na comunidade foram rastreados com suspeita de comprometimento cognitivo, sendo que $7,1 \%$ tiveram o diagnóstico de demência confirmado ${ }^{(4)}$.

\section{Vivenciando as diferentes fases da doença}

A Doença de Alzheimer, considerada como o tipo mais prevalente de demência, pode ser dividida em três fases: fase inicial, intermediária e final, ou ainda classificada como estágios leve, moderado ou avançado ${ }^{(4)}$. A tríade alterações na cognição, alterações de comportamento e dificuldades para o desempenho nas atividades de vida diária marcam a vivência dos cuidadores nas três fases da doença. A categoria vivenciando as fases da doença foi subdivida em três: Vivenciando as alterações cognitivas, vivenciando as alterações de comportamento e vivenciando as dificuldades para o desempenho nas atividades de vida diária, com base na tríade proposta na literatura.

\section{Vivenciando as alterações cognitivas}

Nota-se nos relatos dos familiares, a perda da memória recente, um dos primeiros sintomas a se manifestar:

Ela não lembra de nada, de nada, de nada, só do passado. Se você conversar com ela agora, nem dois minutos ela já esqueceu. (DCZ)

... às vezes ela acabou de almoçar e ela diz que ninguém deu comida pra ela. (OSF)

$\mathrm{Na}$ fase inicial, os esquecimentos e as dificuldades de comunicação são freqüentes, durando em média de dois a quatro anos. A doença de Alzheimer afeta inicialmente a memória de curto prazo. Segundo a literatura, o déficit na memória de curta duração é característica consolidada na doença de Alzheimer, enquanto alteração na memória de longa duração aparece mais tardiamente no curso da doença(4). Um estudo realizado com cuidadores de idosos portadores de Alzheimer, identificou que uma das modificações que o cuidador nota no idoso é o esquecimento ${ }^{(14)}$.

02. Vivenciando as alterações de comportamento

A literatura mostra que a progressão da doença para a fase moderada, que dura em 
torno de três a cinco anos, é percebida por declínio das habilidades mentais e físicas e pelo surgimento de alterações do comportamento. A necessidade de assistência para as atividades de vida diária é conseqüência da desorientação têmporo-espacial, aliada às alterações de memória recente. O paciente age repetindo uma mesma ação ou palavra incessantemente, apresentando também alterações do ciclo sonovigília. Freqüentemente começa a não reconhecer as pessoas ${ }^{(2,4)}$. Estes sinais $\mathrm{e}$ sintomas ficam evidenciados nas seguintes falas:

... o mesmo assunto, o dia todo. Então isso cansou. Ela repetia a mesma coisa. E isso cansava muito a gente. (RMVL)

Os filhos ela também não conhece, praticamente ela não conhece ninguém. (OSF) Então ela falava muito em ir embora, né? E eu falava, Aqui que é a casa da senhora. Aí ela fica toda hora assim, Ai, vamo embora, vamo embora... ela fala assim, Vamo embora, vamo embora. Eu quero ir pra casa da minha mãe. Hoje mesmo,Eu quero ir pra casa da minha mãe. (VLAM)

Ela só lembra do nome da mãe dela, que ela tem em mente que a mãe dela não morreu.... (RMVL)

Episódios de agitação são comuns nos idosos nesta fase da doença e se tornam bastante desgastantes para os próprios pacientes, familiares e profissionais ${ }^{(15)}$. Em conseqüência de episódios de agitação o paciente pode se recusar a fazer certas atividades, sendo difícil para o cuidador. Dentre os fatores que dificultam o cuidado ao idoso com Alzheimer, em estudo sobre o enfrentamento do cuidador, são, segundo as entrevistadas, recusa em alimentar-se, ficar bravo e emburrar ${ }^{(14)}$. Observa-se este fato nas manifestações discursivas dos cuidadores entrevistados nesta pesquisa:

E o mais dificultoso pra mim é o banho...às vezes não consigo, aí ela começa ficar agitada, ela briga, fica violenta, se recusa, aí eu paro, nem dou banho, nada, sabe... (DCZ)
É assim, ela não gosta de muita gente. Reunião familiar ela gosta, mas uma reunião com um grande número de pessoas ela fala: “Minha cabeça fica zonza". Ela não gosta....Ahh...as reuniões, de preferência, na casa dos outros. Mas na minha casa, aí ela já fica bem mais perturbada, porque ela tem medo que alguém vai mexer nas coisas dela. (FRT)

As alterações comportamentais, como a agitação, as perseguições, os relatos de visões, acabam gerando um estresse no cuidador e são prevalentes na maioria dos idosos com demência. Um estudo exploratório-descritivo do tipo série de casos realizado em um serviço de neurogeriatria com o objetivo de descrever as características dos idosos com doença de Alzheimer e seus cuidadores, identificou que para o cuidador, lidar ininterruptamente com o manejo dos distúrbios de comportamento dos idosos pode ser uma das tarefas mais desgastantes $^{(15)}$.

Alguns idosos seguem seus cuidadores, a qualquer lugar aonde vão, como uma "sombra". Isto pode ser visto nas falas seguintes:

Agora ela...onde eu for ela vai. (FRT)

Aonde eu vou ela tá atrás de mim. Se eu vou pra fora ela vai. Às vezes eu deixo ela sentada no sofá pra vim pra cá, sabe? (cozinha). Eu tô lavando a cozinha, eu fico conversando com ela o tempo todo, eu falo, 'Eu tô aqui viu dona Maria, já vou aí na sala'. Ela, 'Tá bom'. De repente eu vejo ela na cozinha eu tenho que por ela na sala pra ela não vim, eu tenho medo dela cair... (DCZ)

Além das alterações de comportamento, os cuidadores relatam a presença de alucinações. E quando elas surgem, o cuidador muitas vezes deixa de realizar o cuidado:

As toalhas penduradas ela acha que é homem, ela acha que a porta tá aberta. Eu vou tirando tudo de perto dela e ela fala, 'Tem gente olhando pra mim'... às vezes ela vê o Seu João na sala, ela fala, 'Eu tenho medo desse homem.(DCZ)

...ela acha que tem homem dentro do banheiro. Ela vê homem dentro do banheiro, ela tem 
Pavarini SCl, Melo LC, Silva VM, Orlandi FS, Mendiondo MSZ, Filizola CLA et al. Cuidando de idosos com Alzheimer: a vivência de cuidadores familiares. Rev. Eletr. Enf. [Internet]. 2008; 10(3):580-90. Available from:

medo, sabe. Ela tem vergonha de tirar a roupa. Eu falo, 'Dona Maria, só tá eu e a Senhora'. Tá, aí ela tira, eu ajudo a tirar. Aí a hora que chega na calcinha ela não tira, pra ela tem gente olhando. Ela sente vergonha. Teve um dia que ela chegou a chorar, ela chorou que não queria tomar banho, daí eu coloquei a roupa dela e não dei. (DCZ)

Alucinações e delírios são freqüentemente relatados pelos cuidadores. As alterações de comportamento geram estresse ao cuidador, sendo necessárias condições para saber como lidar com a demência, no sentido de proporcionar ao idoso demenciado, carinho, apoio físico e emocional, promovendo maior segurança e minimizando tensões que, por ventura ocorram. Dados semelhantes foram encontrados em outros estudos brasileiros ${ }^{(15-16)}$.

A evolução progressiva da doença traz como conseqüência a dependência, levando à necessidade de cuidados. Por isso, a demência não afeta somente a qualidade de vida do paciente, mas também a dos familiares/cuidadores. Os projetos do futuro desses familiares podem ficar prejudicados e esses se sentem sobrecarregados, limitados, com sentimento de desespero, desequilíbrio, frustração e angústia, muitas vezes causando conflitos entre os membros da família ${ }^{(16)}$. Pelo fato da doença ser degenerativa e não apresentar cura ${ }^{(4)}$, o papel de cuidador torna-se cada vez mais difícil:

É difícil...é difícil...muita paciência, muita calma, porque se não... (LMP)

Olha, é um papel assim, bastante difícil, porque é uma luta sem retorno. (AMMP)

À medida que a doença vai evoluindo, a dependência do idoso também aumenta progressivamente ${ }^{(3)}$. As alterações de comportamento dos pacientes com demência, como agitação, agressividade, delírios e alucinações, trazem um enorme desgaste para o cuidador ${ }^{(15)}$.

Foi uns dias muito difícil pra nós. Aí eu falei, não pai, vamos tentar, ela tá doente, não é uma coisa normal. (RMVL)

Ah cansa, cansa um pouco, você fica mais estressada, mas eu tô conseguindo. (RMVL) Ai cansada, mas assim cansada a mente, sabe. (DCZ)

Por fim, na fase final da doença de duração entre um a três anos, o que mais se evidencia é a dependência do idoso. Devido à imobilidade, ele também corre o risco de apresentar co-morbidades como úlcera de pressão, perda de peso, pneumonia entre outras $^{(17)}$.

Nesta fase, a dependência avança e o idoso geralmente necessita de seu cuidador para a realização das atividades de vida diária, tanto as básicas quanto as instrumentais.

03. Vivenciando as dificuldades para o desempenho nas atividades de vida diária

Dentre as atividades básicas, para os cuidadores entrevistados, o banho é a mais difícil, como exemplificado a seguir:

O banho é super difícil, sempre tem que levar ela, ajudar ela a tirar toda a roupa, você tem que dar o sabonete na mão dela, dar a bucha e falar, 'Mãe esfrega aqui, esfrega ali', né? Ajudar ela a esfregar. A gente fala, 'Mãe, passa bastante sabonete'. Agora, se você não dá o sabonete, toalha na mão dela... O pé, você fala, 'Mãe, enxuga que tá molhado que eu vou ajudar a mãe'. É uma ajuda constante. (RMVL)

O banho pode ser causa de momentos estressantes e perigosos para o idoso com demência. Já na fase inicial da doença, pode persistir uma resistência ao ato de tomar banho ou de ser banhado.

...eu peguei ela no sábado e ela já tava mais agitada. Ela não queria mais tomar o banho, ela tirou metade da roupa e não queria mais tirar o resto. Ela ficou terrível. (RMVL)

E o mais dificultoso pra mim é o banho, eu tiro a roupa dela ela não quer, eu insisto umas três, quatro vezes, às vezes eu consigo, às vezes não consigo... (DCZ)

Aí tem hora que ela bate o pé né, aí fica mais difícil em matéria mesmo do banho, aí dá até medo né, por que se ela fala que não quer 
Pavarini SCl, Melo LC, Silva VM, Orlandi FS, Mendiondo MSZ, Filizola CLA et al. Cuidando de idosos com Alzheimer: a vivência de cuidadores familiares. Rev. Eletr. Enf. [Internet]. 2008;10(3):580-90. Available from:

tomar banho, vai ficar suja. (VLAM)

O tipo e o grau de ajuda na manutenção dos cuidados sobre higienização que o idoso necessita dependem de suas condições físicas, cognitivas e psicoafetivas. Algumas vezes é necessário criar estratégias e contar com outros membros da família. O relato a seguir mostra uma estratégia criada por uma das entrevistadas, que conta com a intermediação da bisneta do idoso para supervisionar e orientar no banho.

Ela entra sozinha. Aí eu ensinei a minha neta...tem um vão na porta, na porta do banheiro e a Júlia já tem esse costume de ficar espiando...Vê se a vovó ligou o chuveiro. Então a Júlia olha: 'O Biza, liga o chuveiro, Biza, entre embaixo, Biza'.... Fica dando as coordenadas pra ela, sabe, fica olhando ela e dando as coordenadas pra ela. Mas assim, tá difícil, tá muito difícil. Ela não aceita ainda....porque ela tem aqueles lances de lucidez, então ela..nisso ela não é doente, você entendeu, ela não é doente. (FRT)

Além do banho, outras atividades básicas são relatadas, como sendo também de difícil realização como vestir-se, pentear-se, ir ao toalete:

Aí ela vestia, ela ainda se trocava, mas ela esqueceu como vestia a saia, punha o zíper pra frente, ou ela punha três ou quatro peças de roupa, toda roupa que ela achava que era dela, ela punha uma por cima da outra, aí foi chegando uma hora que não teve mais como deitar sozinha. (RMVL)

...quando leva ela no banheiro ela esqueceu como levantar a saia e tirar a calcinha. Ela fica parada. Isso tem acontecido de uns dois meses pra cá. Não é toda hora. Ela vai pra fazer xixi, mas a gente tem que lembrar ela. Agora onde senta, o vaso, a gente tem que mostrar tudo pra ela. Aí pra lavar a mão, eu não sei se é o fato dela não enxergar bem, eu dou o sabonete na mão dela, coloco debaixo da água, aí ela percebe que é ali que ela tem que lavar. Se não ela não sabe onde é que ela vai lavar. Ela fica 'É aqui', ela fica meio perdida. (RMVL)

A dificuldade dela agora é ir no banheiro. Ela não sabe como tirar a calcinha pra ir no banheiro. Eu ajudo, ela não quer, ela tá totalmente uma criança sabe... (DCZ)

Um cuidador refere algumas adaptações para facilitar o desenvolvimento do cuidado, já que reconhece que além do ambiente, as roupas e os calçados devem ser adaptados para que o idoso mantenha a máxima autonomia e a mínima dependência:

Ela usava sempre saia e blusa. Agora nós estamos mudando. Estamos colocando vestido por que é uma peça só, é mais fácil. Quando ela ficava sozinha e usava saia, a gente chegava aqui, ela tava com o zíper pra frente. Teve um dia que eu cheguei, a barra da saia tava em cima e o zíper pra baixo. E ela prendeu com o grampo de cabelo. (RMVL)

Uma pesquisa realizada com 20 cuidadores familiares de pacientes com doença de Alzheimer, acompanhados em um hospital universitário público, e 20 cuidadores de idosos de uma clínica privada identificou que com relação aos fatores de estresse físico e psíquico no cuidado dos pacientes, $82,5 \%$ dos cuidadores afirmaram que não houve necessidade de fazer mudanças na casa em função do agravamento da doença e 17,5\% referiram mudanças como adaptações de banheiro e/ou quartos ${ }^{(18)}$.

$\mathrm{Na}$ fase mais avançada da doença, pode ocorrer falta de controle dos esfíncteres, as denominadas incontinência urinária e fecal.

...a hora que eu voltei...já tinha posto a mão no coco, já tava suja sabe, já tinha feito anarquia. (VLAM)

...eu chego e vejo o banheiro molhado, ela com a roupa molhada cheirando urina. (DCZ)

As Atividades Instrumentais da Vida Diária (AIVD) são consideradas mais complexas do que as tarefas no domínio do cuidado pessoal e incluem atividades como fazer compras, manusear dinheiro, preparar alimentos, utilizar 
Pavarini SCI, Melo LC, Silva VM, Orlandi FS, Mendiondo MSZ, Filizola CLA et al. Cuidando de idosos com Alzheimer: a vivência de cuidadores familiares. Rev. Eletr. Enf. [Internet]. 2008;10(3):580-90. Available from:

o fogão de forma segura, tomar medicação, lembrar de acontecimentos importantes, capacidade de sair de casa sozinho e encontrar o caminho de volta, entre outras ${ }^{(19)}$. O desempenho dessas atividades é afetado como podemos verificar nos exemplos a seguir:

...ela foi esquecendo como lavava a louça. Não podia mais deixar o fogão ligado que ela ia lá, acendia, esquecia.(RMVL)

Faz mais ou menos um mês que eu tirei, e desliguei o fogão da casa. Então eu esquento tudo pra ela no microondas em cima, no meu filho. Porque ela fez duas vezes isso...esquentando o leite, esqueceu... aí eu tava ocupada com a neta...aquelas coisas todas né. Esqueceu, o leite acabou, queimou o leite, queimou, a casa enfumaçada...ela não percebeu. Ela fez duas vezes. E numa outra vez eu fui lá, que eu tava pra fora, na hora que eu entrei eu senti o cheiro de gás. O gás ligado. Então não deixo mais...'Mãe vai tomar leite?' 'Vou'...então eu esquento. Eu faço o prato dela, esquento no microondas, a gente senta e come junto, tá. Ela come sozinha, mas ela não prepara mais nada, nem o leite dela, por causa de acidente. Entendeu? Porque mesmo quando ela prepara ela toma e esquece que tomou. Aí eu tenho que fazer novamente. (FRT)

As Atividades Instrumentais envolvem habilidades mais complexas, as quais incluem um planejamento e a garantia da memória preservada. Idosos com demência possuem déficit da memória e da capacidade de planejar condutas adequadas. Portanto, para as atividades instrumentais os idosos tornam-se mais dependentes inicialmente do que para as atividades básicas da vida diária ${ }^{(19)}$.

\section{Vivenciando o papel de cuidador}

Cuidar de um idoso demenciado pode causar um impacto emocional, afetivo e um desgaste físico para os cuidadores em suas vidas uma vez que a pessoa torna-se progressivamente dependente ${ }^{(9-12)}$. Esta situação, agravada com a presença dos transtornos demenciais provoca grande sofrimento tanto para os pacientes quanto para seus familiares, os quais são obrigados a se reorganizarem para viabilizarem os cuidados à pessoa que adoece e torna-se progressivamente dependente. Muitas vezes, um familiar assume a função de cuidador, e passa a viver em função dessa nova tarefa.

...foi a hora que começou o início do tratamento, foi aí que levaram ela pra fazer o exame de cabeça. Mas nessa época, não era eu que cuidava. Até então, era minha outra irmã por que eu ainda tava trabalhando. Aí quando eu me afastei, que passou tudo pra mim foi quando nós descobrimos que era o Alzheimer... (RMVL)

Cuidar de idosos dependentes pode causar impacto emocional e uma sobrecarga para os cuidadores $^{(9)}$. Esse impacto ou sobrecarga é definido como problemas físicos, psicológicos ou emocionais, sociais e financeiros que familiares apresentam como conseqüência de cuidar de idosos doentes ${ }^{(20)}$. Relatos de estresse, afastamento da vida social e do trabalho, além dos transtornos físicos ou psicológicos estão presentes no discurso dos cuidadores:

É...olha...eu quero que fique bem claro um ponto. Eu tô extremamente estressada, eu tô tomando antidepressivo, tô tomando ansiolítico, e o mesmo médico dela é meu, tanto o geriatra quanto o cardiologista. Então, nos conhecem eu e ela...eles sabem como é minha rotina. Ah...eu fui até esses dias no médico...Eu quero parar de toma remédio...ele dobrou, ele dobrou a medicação, né. De um mês pra cá, especialmente, tô muito, mas muito, emocionalmente, mentalmente...Eu cheguei a semana retrasada a tomar o remédio dela, o Riminil, passei mal, mas aí liguei pro médico, ele disse normal e tal. Mas, não é só pelos cuidados com ela, isso que eu quero que fique claro. Acho que se eu vivesse só eu e ela, a carga seria bem menor, tá. Mas eu tenho meu filho, minha nora e minha neta. (FRT)

Alguns cuidadores relatam a necessidade premente de uma rede de suporte familiar e social, especialmente destinado aos cuidadores, 
Pavarini SCl, Melo LC, Silva VM, Orlandi FS, Mendiondo MSZ, Filizola CLA et al. Cuidando de idosos com Alzheimer: a vivência de cuidadores familiares. Rev. Eletr. Enf. [Internet]. 2008;10(3):580-90. Available from:

para facilitar as discussões, as trocas de experiências e a transmissão de conhecimentos sobre as maneiras de cuidar do idoso com Alzheimer, além de aliviar as expectativas e os efeitos ansiogênicos gerados pelo processo de cuidar. Neste sentido, a Associação Brasileira de Alzheimer, uma entidade sem fins lucrativos, formada por familiares e profissionais de diversas áreas tem um papel fundamental no apoio ao cuidador do paciente com Alzheimer. Os cuidadores entrevistados manifestaram o desejo que "seria bom todos ajudarem".

...agora ela já estando estabilizada e já conhecendo qual é a realidade, então todos ajudam com os cuidados com ela, né. (EFN)

Agora um apoio moral de todos os filhos, isso tá faltando, por que eles tão deixando muito a mercê de nós, eu, a L. e mais a D. (RMVL)

Quando existem outros problemas de saúde com os demais membros da família, a sobrecarga do cuidador principal fica potencialmente aumentada, podendo gerar maior efeito ansiogênico, estresse e outros transtornos do humor, além de ser uma fonte provável de conflitos, conforme observado na fala seguinte:

Olha, todos têm um problema. Eles moram todos longe da minha casa. Eu tenho meu irmão mais velho, que ele fala que ele não...que não gosta do termo que usa, ele tem problema de TOC...transtorno obsessivo compulsivo...aham...já deixou louco acho que uns 10 psicólogos. Ele deixa, ele deixa. Então, ele tem problemas...tem pânico, tem fobia. Então ele me ajuda. De que forma? Eu converso às vezes com ele. Mas pelo fato de ele ser uma pessoa problemática, sabe, não se vê que ela...ele não tem isenção nas opiniões dele, ele é uma pessoa cheia de preconceitos, de tabus. Dentro das possibilidades dele, ele tenta me ajudar. Quando eu preciso sair, vez ou outra ele fica com ela. Mas ele já não tem tanta paciência, porque ele morava com ela junto, antes. Ele falou pra mim: 'Eu entrego nas suas mãos, eu não tenho paciência, eu não agüento mais'. Isso antes de ser diagnosticado o
Alzheimer.. (FRT)

O contexto familiar pode apresentar outras exigências de cuidados além daqueles necessários ao idoso com demência. Filhos e irmãos e outras patologias se somam à sobrecarga do cuidador, incluindo o seu próprio adoecer. Quando entrevistados cuidadores de idosos com demência em um serviço universitário federal do Estado de São Paulo, foram referidos problemas de saúde por $48,3 \%$ dos sujeitos pesquisados, sendo relatadas até três co-morbidades ${ }^{(9)}$.

É...Não...tem que ter. Ainda não tive, como eu falei pra você. Precisou meu irmão falar: "Ó, tá na hora de você procurar ajuda com alguém", porque eu já não tava dando conta. Por conta do...do peso, porque como ela já não levanta, ela não andava, ela já não levantava mais, eu tinha que puxa-la da cama pra sentar ela, pra tentar leva... pra ver ela andando, ou na cadeira de rodas. E eu tenho...como eu sou mastectomizada, eu tenho a dificuldade no braço direito, né. Eu não tenho a musculatura toda do lado. Então, isso me, me, como eu te falei, me causou um pouco de desconforto na época que eu não tava conseguindo cuidar dela. Eu...eu me sentia com dor, eu via ela, ela...ela piorando. Então foi isso que naquela fase ali, eu acho que causou a labirintite, me causou um tipo de uma depressão. (MJ QS)

É preciso ter clareza do tipo e da quantidade de ajuda que o cuidador precisa para desempenhar a tarefa de cuidar de um familiar com demência. Um estudo realizado com cuidadores primários familiares identificou que com relação à divisão da tarefa de cuidar, $79,3 \%$ dos entrevistados contavam com auxilio de outra pessoa. A grande maioria $(96,9 \%)$ realizava outras atividades além do cuidado com o idoso. Mais de $50 \%$ dos cuidadores realizavam quatro ou mais tarefas com os idosos como higiene, banho, administrar medicação, preparar e administrar alimentação, auxiliar na mobilidade, no vestuário e fazer curativos $^{(9)}$. 
Pavarini SCl, Melo LC, Silva VM, Orlandi FS, Mendiondo MSZ, Filizola CLA et al. Cuidando de idosos com Alzheimer: a vivência de cuidadores familiares. Rev. Eletr. Enf. [Internet]. 2008;10(3):580-90. Available from:

\section{CONCLUSÃO}

As entrevistas permitiram compreender o processo de vivenciar o cuidado a idosos demenciados na visão do cuidador familiar de idosos com Alzheimer.

Os resultados mostram que para os entrevistados os primeiros sintomas da doença geralmente são confundidos com o próprio processo de envelhecimento.

A evolução da doença de Alzheimer acarreta a perda de autonomia e independência, as quais se constituem uma geradora de grande dependência dos idosos e sofrimento e sobrecarga para familiares e particularmente aos cuidadores. As alterações do comportamento por parte do idoso causam grandes dificuldades para os cuidadores entrevistados. Os familiares passam a enfrentar situações com as quais ainda precisam aprender a lidar. Novas identidades, novos papéis, novas situações passam a ser vivenciadas pelos cuidadores e pelos idosos. Ambos parecem precisar reaprender a viver neste novo cenário. Os resultados são semelhantes a outros estudos brasileiros que caracterizam os cuidadores de idosos com demência e avaliam o impacto da tarefa de cuidar.

Cuidar de idosos com demência depende da fase da doença, da qualidade da rede de suporte familiar, da história de vida de cada família e da forma como cada família enfrenta a situação. É, sem dúvida, uma experiência muito pessoal. Compreender como os cuidadores vivenciam esta experiência pode ajudar profissionais da saúde no planejamento de programas de orientação aos cuidadores.

Os cuidadores entrevistados apontam ainda, a necessidade de uma rede de apoio familiar e de suporte social. Não se trata de um único cuidador, mas de várias pessoas auxiliando em diferentes tipos de cuidado. Instrumentos que avaliam a rede de apoio familiar aos idosos podem ajudar a compreender a estrutura que estas famílias dispõem.

Investigações sobre o uso do genograma e do ecomapa, por exemplo, com familiares de idosos demenciados poderiam trazer resultados importantes para o planejamento do cuidado ao idoso e para auxiliar nos programas de orientação aos cuidadores.

No contexto brasileiro, muitas perguntas ainda precisam ser respondidas na temática cuidando do idoso com Alzheimer.

\section{REFERÊNCI AS}

1. Instituto Brasileiro de Geografia e Estatística. Censos demográficos. Brasília (Brasil): Ministério do Planejamento, Orçamento e Gestão; 2007.

2. Reyes PF, Shi F. Dementias: etiologies and differential diagnoses. Barrow Quarterly. 2006; 22(1): 4-8.

3. Gratão ACM. Demanda do cuidador familiar com idoso demenciado [dissertação]. [Ribeirão Preto]: Escola de Enfermagem/USP; 2006. 89p.

4. Bottino CMC, Lacks J, Blay SL. Demência e transtornos cognitivos em idosos. Rio de J aneiro: Guanabara Koogan; 2006.

5. Scazufca M, Cerqueira ATAR, Menezes PR, Prince M, Vallada HP, Miyazaki MCOS et al. Investigações epidemiológicas sobre demência nos países em desenvolvimento. Rev. Saúde Pública [Internet]. 2002 [cited 2007 jan 14];36(6):773-8. Available from: http://www.scielo.br/pdf/rsp/v36n6/13535.pdf.

6. American Psychiatry Association. Diagnostic and statistical manual of mental disorders (DSM-IV). $4^{\text {th }}$ ed. Washington: American Psychiatry Association; 1994.

7.Luzardo AR, Gorini MIPC, Silva APS. Características de idosos com doença de Alzheimer e seus cuidadores: uma série de casos em um serviço de neurogeriatria. Texto e Contexto Enfermagem. 2006; 15(4): 94-587.

8. Organização Mundial da Saúde. Relatório sobre a saúde no mundo 2001: Saúde mental, nova concepção, nova esperança. Geneva (Suíça): Organização Mundial da Saúde; 2001.

9. Lemos ND, Gazzola JM, Ramos LR. Cuidando do paciente com Alzheimer: o impacto da doença no cuidador. Saúde e Sociedade. 2006; 15(3): 170-9.

10. Balardy L. Predictive factors of emergency hospitalization in Alzheimer's patients: results of one-year follow-up in the REAL.FR Cohort. J Nutr Health Aging. 2005; 9(2): 112-6.

11. Torti FM, Gwyther LP, Reed SD, Friedman 
Pavarini SCl, Melo LC, Silva VM, Orlandi FS, Mendiondo MSZ, Filizola CLA et al. Cuidando de idosos com Alzheimer: a vivência

de cuidadores familiares. Rev. Eletr. Enf. [Internet]. 2008;10(3):580-90. Available from:

http://www.fen.ufg. br/revista/v10/n3/v10n3a04.htm.

JY, Schulman KA. A multinational review of recent trends and reports in dementia caregiver burden. Alzheimer Dis Assoc Disord. 2004; 18(2): 99-109.

12. Patterson TL, Grant I. Interventions for caregiving in dementia: physical outcomes. Curr Opin Psychiatr. 2003; 16(6):629-33.

13. Bardin L. Análise de Conteúdo. 1a edição. Lisboa (Portugal): Edições 70; 1977.

14. Caldeira APS, Ribeiro RCHM. O enfrentamento do cuidador do idoso com alzheimer. Arq Ciênc Saúde. 2004;11(2):100104.

15. Luzardo AR, Gorini MIP, Silva APSS. Características de idosos com Doença de Alzheimer e seus cuidadores: uma série de casos em um serviço de neurogeriatria. Texto Contexto Enferm. 2006; 15(4): 587-94.

16. Lemos ND, Gazzola JM, Ramos LR Cuidando do paciente com Alzheimer: o impacto da doença no cuidador. Saude Soc. 2006; 15(3): 170-9.

17. Savonitti BHRA. Cuidando do idoso com demência. In: Duarte YAO, Diogo MJD. Atendimento domiciliar: um enfoque Gerontológico. São Paulo: Atheneu; 2000. p.421-438.

18. Vilela LP, Caramelli P. A doença de Alzheimer na visão de familiares de pacientes. Rev Assoc Med Bras. 2006; 52(3): 148- 52.

19. Novelli MMPC. Adaptação transcultural da escala de qualidade de vida na doença de Alzheimer [dissertação]. [São Paulo]: Faculdade de Medicina da Universidade de São Paulo/USP; 2003. 130p.

20. Cattani RB, Girardon-Perlini NMO. Cuidar do idoso doente no domicílio na voz de cuidadores familiares. Revista Eletrônica de Enfermagem [Internet]. 2004 [cited 2006 jan 14];6(2). Available from: URL: http://www.fen.ufg.br/revista/revista6_2/idoso.html.

Artigo recebido em 09.08.07

Aprovado para publicação em 30.09.08 